\title{
Uranyl Complexes as Scaffolding or Spacers for Cucurbit[6]uril Molecules in Homo- and Heterometallic Species, Including a Novel Uranyl-Lanthanide Complex
}

\author{
Pierre Thuéry, $*$,[a] \\ ${ }^{[a]}$ NIMBE, CEA, CNRS, Université Paris-Saclay, CEA Saclay, 91191 Gif-sur-Yvette, France \\ E-mail: pierre.thuery@cea.fr \\ http://iramis.cea.fr/nimbe/
}

Keywords: Uranium(VI) / Cucurbiturils / Structure elucidation / Heterometallic complexes / Anion encapsulation

\begin{abstract}
Reaction of uranyl nitrate with cucurbit[6]uril (CB6) and carboxylic or sulfonic acid ligands under hydrothermal conditions and in the presence of additional metal cations $\left(\mathrm{K}^{\mathrm{I}}\right.$ or $\left.\mathrm{Ce} \mathrm{e}^{\mathrm{III}}\right)$ or co-solvents provided four complexes which were crystallographically characterized. $\left[\left(\mathrm{UO}_{2}\right)_{2} \mathrm{~K}_{2}(\mathrm{CB} 6)(\mathrm{adc})_{2}\left(\mathrm{NO}_{3}\right)_{2}\left(\mathrm{H}_{2} \mathrm{O}\right)_{2}\right] \cdot 5 \mathrm{H}_{2} \mathrm{O} \quad(\mathbf{1})$, where $\mathrm{H}_{2}$ adc is 1,3-adamantanedicarboxylic acid, crystallizes in the form of a central $\mathrm{K}_{2}(\mathrm{CB} 6)^{2+}$ column surrounded by two one-dimensional (1D) polymeric $\mathrm{UO}_{2}(\mathrm{adc})\left(\mathrm{NO}_{3}\right)^{-}$chains attached to the column by nitrate bridges, with a perfect match of the repeat lengths in the two subunits. The longer 1,3-adamantanediacetic acid $\left(\mathrm{H}_{2}\right.$ adac $)$ gives the complex $\left[\left(\mathrm{UO}_{2}\right)_{2}(\mathrm{adac})_{2}(\mathrm{HCOOH})_{2}\right] \cdot \mathrm{CB} 6 \cdot 6 \mathrm{H}_{2} \mathrm{O}(2)$ in which the 1D uranyl-containing polymer and columns of CB6 molecules form a layered arrangement held by weak $\mathrm{CH}$..O hydrogen bonds. The complex formed with the di-potassium salt of methanedisulfonic acid $\left(\mathrm{K}_{2} \mathrm{mds}\right),\left[\left(\mathrm{UO}_{2}\right)_{2} \mathrm{~K}_{2}(\mathrm{CB} 6)(\mathrm{mds})_{2}(\mathrm{OH})_{2}\left(\mathrm{H}_{2} \mathrm{O}\right)_{8}\right] \cdot 4 \mathrm{H}_{2} \mathrm{O}(3)$, is a $1 \mathrm{D}$ polymer in which $\mathrm{K}_{2}(\mathrm{CB} 6)^{2+}$ units are connected to one another by doubly hydroxide-bridged uranyl dimers in which the disulfonates are terminal, chelating ligands; connection between the two subunits is solely through potassium oxo-bonding to uranyl. The complex $\left[\left(\mathrm{UO}_{2}\right)_{2} \mathrm{Ce}_{2}(\mathrm{CB} 6)\left(\mathrm{C}_{2} \mathrm{O}_{4}\right)_{3}\left(\mathrm{NO}_{3}\right)_{4}\left(\mathrm{H}_{2} \mathrm{O}\right)_{6}\right] \cdot 2 \mathrm{H}_{2} \mathrm{O}(4)$ is a $1 \mathrm{D}$ polymer containing bridging oxalate ligands formed in situ, in which CB6 is coordinated to the lanthanide cations only; one nitrate and one water ligands hydrogen bonded to each other are included in the CB6 cavity, with the possible occurrence of interactions between nitrate oxygen atoms and ureido carbon atoms.
\end{abstract}




\section{Introduction}

The complexing properties of cucurbit $[n]$ urils $(\mathrm{CB} n, n=5-8)^{[1]}$ toward f-element cations, either lanthanides (4f) or actinides (5f) have attracted much interest in recent years. In the case of actinides, one incentive for such work, besides its relevance for structural inorganic chemistry and metal-organic polymer studies, is the potential of these macrocycles for removal of uranyl, or more generally actinyl, cations from nuclear wastes. ${ }^{[2]}$ Cucurbiturils proved to be efficient ligands for lanthanide cations, ${ }^{[1 j, 3]}$ which are generally bound to at least one (most often two or three) carbonyl groups, although examples of second sphere coordination mediated by water molecules or organic ligands have also been found. ${ }^{[3 \mathrm{~h}, \mathrm{j}, \mathrm{k}]}$ Both first- and second-sphere complexes have been described with thorium(IV) ${ }^{[4]}$ and uranyl cations, ${ }^{[5]}$ and the first polyrotaxanes including uranyl-containing threads and CB6 macrocyclic beads were also recently reported. ${ }^{[6]}$ An interesting case is that in which uranyl cations are reacted with $\mathrm{CBs}$ in the presence of carboxylic or sulfonic acids: coordination to both species of ligands occurs in some cases, ${ }^{[5 f, \mathrm{~g}, \mathrm{i}]}$ but a frequent outcome is coordination of uranyl to the carboxylate or sulfonate ligands only, the CB molecule being either free or complexed to alkali or alkaline-earth metal cations, or involved in weak interactions with ammonium cations. ${ }^{\left[{ }^{[-j}-j\right]}$ In the latter cases, association of the uranyl complex subunit, sometimes polymeric, and the macrocycles, through ion-dipole or hydrogen bonding interactions, or coordination bonds mediated by alkali or alkaline-earth cations, has been shown to be a source of original architectures. In particular, the tendency of uranyl-containing coordination polymers ${ }^{[7]}$ to give undulating layers matches with the propensity of CB6 to pack into columns, which results in assemblies in which the former are draped around the latter. ${ }^{[5 \mathrm{~g}]}$ The present work reports novel results obtained in this family of uranyl complexes with mixed ligands. Although many carboxylic and sulfonic acids have been tried in the present as well as in previous experiments, most did not 
give any exploitable crystalline material, and the results presented here involve some very different ligands which allowed to grow crystals suitable for X-ray crystallography. These ligands are oxalic acid (generated in situ), 1,3-adamantanedicarboxylic acid $\left(\mathrm{H}_{2} \mathrm{adc}\right)$, 1,3-adamantanediacetic acid $\left(\mathrm{H}_{2} \mathrm{adac}\right)$, and the di-potassium salt of methanedisulfonic acid $\left(\mathrm{K}_{2} \mathrm{mds}\right)$. Oxalate is a very common ligand for uranyl ions, with more than 150 crystal structures reported in the Cambridge Structural Database (CSD, Version 5.38) ${ }^{[8]}$ but the adamantane-based dicarboxylates have been the subject of few reports. ${ }^{[9]}$ Sulfonates are not frequently used to generate uranyl-organic polymeric assemblies, ${ }^{[5 h, i, k, 1,10]}$ and there is no case reported with the simplest disulfonate, $\mathrm{mds}^{2-}$. While heterometallic complexes uniting uranyl and lanthanide cations are generally not extremely common, ${ }^{[10 a, 11]}$ several such species were found that involve CB6 ligands, ${ }^{[5 \mathrm{c}, \mathrm{k}]}$ which show that, in the additional presence of a sulfonate ligand, the lanthanide cation binds preferentially to CB6, and the uranyl cation to the sulfonate groups. ${ }^{[5 \mathrm{k}]}$ A novel uranyl-lanthanide-CB6 complex is described herein, the first to involve a carboxylate co-ligand.

\section{Results and Discussion}

The asymmetric unit in the complex $\left[\left(\mathrm{UO}_{2}\right)_{2} \mathrm{~K}_{2}(\mathrm{CB} 6)(\operatorname{adc})_{2}\left(\mathrm{NO}_{3}\right)_{2}\left(\mathrm{H}_{2} \mathrm{O}\right)_{2}\right] \cdot 5 \mathrm{H}_{2} \mathrm{O}$ (1) contains one uranyl and one potassium cations, one $\operatorname{adc}^{2-}$ and one nitrate ligand, and half a centrosymmetric CB6 molecule (Figure 1). The uranium atom is chelated by two carboxylate groups from two $\operatorname{adc}^{2-}$ anions and one nitrate ion, its environment being thus hexagonal bipyramidal [U-O(oxo) bond lengths $1.783(4)$ and 1.774(4) $\AA$, U-O(carboxylate) 2.415(4)2.485(4) A, U-O(nitrate) 2.501(4) and 2.517(4) $\mathrm{A}$. A simple, single-stranded one-dimensional (1D) polymer running along the $a$ axis is thus generated, which differs from the ribbon- or braidshaped ones previously described in homometallic uranyl complexes including coordinated solvent 

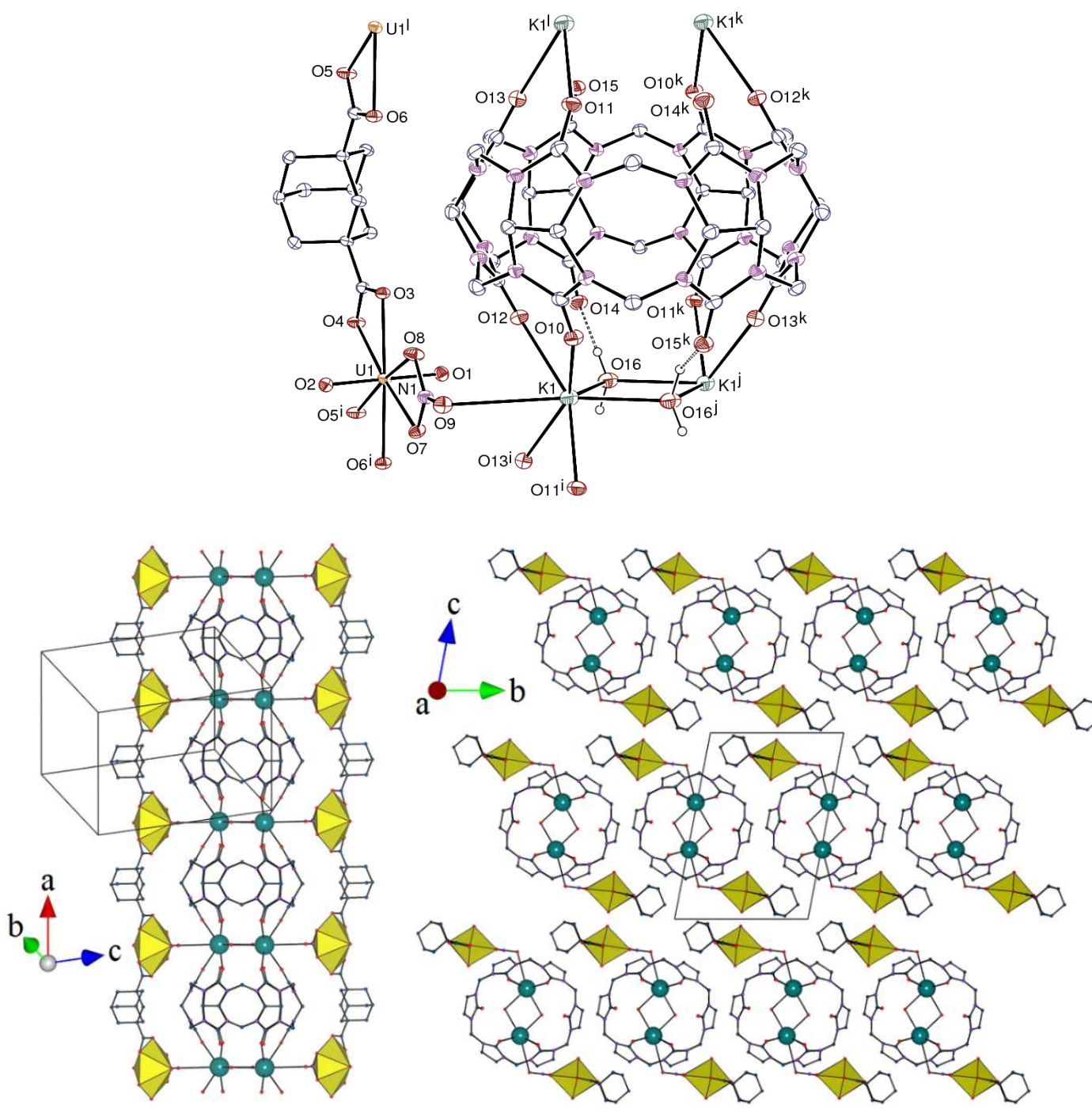

Figure 1. Top: view of compound 1. Displacement ellipsoids are drawn at the $30 \%$ probability level. The solvent molecules and the carbon-bound hydrogen atoms are omitted. The hydrogen bonds are shown as dashed lines. Symmetry codes: $\mathrm{i}=x+1, y, z ; \mathrm{j}=1-x, 2-y, 1-z ; \mathrm{k}=-x, 2-y, 1-z ; 1=x-1, y, z$. Bottom: views of the 1D polymer (left) and the packing parallel to the chain axis (right); the uranium coordination polyhedra are colored yellow and potassium atoms are shown as blue spheres, solvent molecules and hydrogen atoms are omitted.

molecules (water, $N, N$-dimethylformamide or $N$-methyl-2-pyrrolidone). ${ }^{\left[{ }^{a}, \mathrm{~b}\right]}$ Two potassium cations bridged by two water molecules are each bound to four carbonyl groups from two CB6 
molecules, thus forming a 1D polymer running along the $a$ axis. A similar arrangement, with water replaced by hydroxide bridges, was found in the potassium complex of $\mathrm{CB} 6$; $^{[12]}$ the $\mathrm{K}-\mathrm{O}$ (carbonyl) bond lengths of 2.689(4)-2.764(4) $\AA$ in 1 are slightly shorter than those in the latter complex, 2.784(3) and 2.794(3) $\AA$. The K-O(water) bond lengths of 2.693(5) and 2.729(5) $\AA$ are comparable to the average value of 2.82(12) $\AA$ for the 262 cases of bridging water molecules reported in the CSD. A seventh, longer contact between potassium and the nitrate oxygen atom O9 not bound to uranyl, at 3.387(5) $\AA$, makes for a distorted capped trigonal prismatic environment, with the loosely coordinated atom 09 in the capping position. The water molecules are hydrogen bonded to

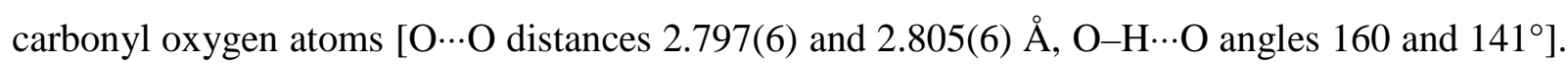
The CB6 molecule presents some ellipsoidal distorsion, with $\mathrm{O} \cdots \mathrm{O}$ distances between oxygen atoms facing one another across the portal of 6.419(6), 6.773(6) and 7.439(6) A, the longest one corresponding to the uncoordinated oxygen atoms. Both the $\left[\mathrm{UO}_{2}(\operatorname{adc})\left(\mathrm{NO}_{3}\right)\right]^{-}$anionic uranylcontaining polymer and the cationic $\left[\mathrm{K}_{2}(\mathrm{CB} 6)\left(\mathrm{H}_{2} \mathrm{O}\right)_{2}\right]^{2+}$ columns run side-by-side with a $2: 1$ stoichiometry, and the perfect size match between the repeat units of both (equal to the $a$ axis unit length) ensures that the uranium $\cdots$ uranium and potassium $\cdots$ potassium distances along the axis are equal, these atoms being located in planes perpendicular to the polymer chain axis. This results in the CB6 columns appearing to be propped by uranyl-based scaffolding, the connection between these subunits being through weak potassium bonding to nitrate. Analysis of the Hirshfeld surface $^{[13]}$ calculated with CrystalExplorer ${ }^{[14]}$ shows that, apart from this potassium-nitrate bonding, there is no interaction exceeding dispersion between the two subunits. The packing is such that layers of columns stacked in a bump-to-hollow fashion lie parallel to $\left(\begin{array}{lll}0 & 0 & 1\end{array}\right)$, adjacent layers along the $c$ axis facing each other through the $\left[\mathrm{UO}_{2}(\operatorname{adc})\left(\mathrm{NO}_{3}\right)\right]^{-}$chains. Two complexes of terbium(III) with adc ${ }^{2-}$ and CB6 were previously described, which crystallize either as a three- 
dimensional (3D) framework, or an assembly uniting alternate layers of CB6 and a planar, twodimensional (2D) terbium-adc ${ }^{2-}$ polymer, and which differ from the present complex by the direct coordination of $\mathrm{Tb}^{\mathrm{III}}$ to $\mathrm{CB} 6$ in the first case, and the absence of bonding between the two subunits in the second. ${ }^{[3 r]}$

Replacement of 1,3-adamantanedicarboxylic acid by 1,3-adamantanediacetic acid, in which the two acid groups are separated by five carbon atoms instead of three, provides the complex
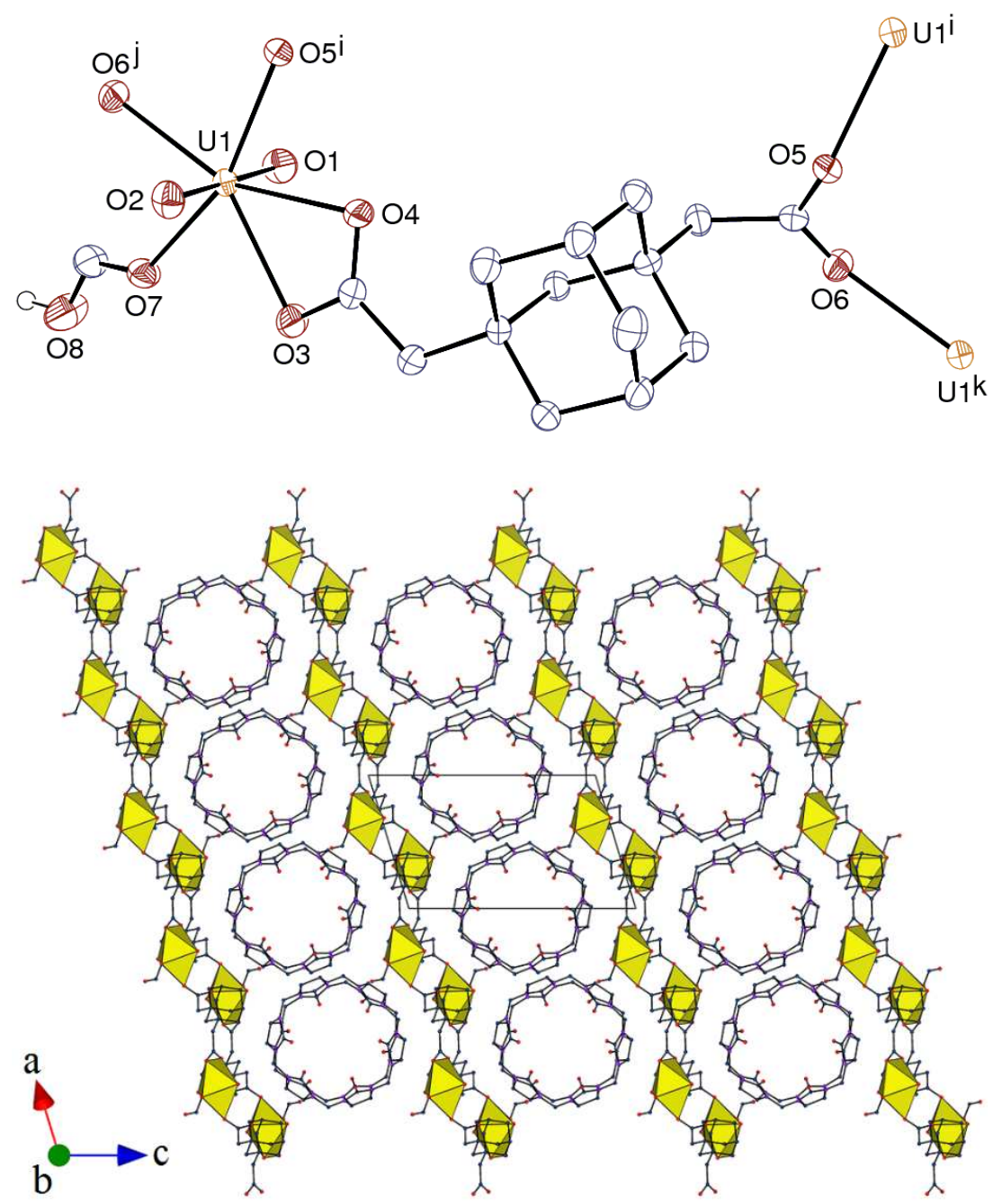

Figure 2. Top: view of the uranyl complex in 2. Displacement ellipsoids are drawn at the 50\% probability level. The solvent molecules and carbon-bound hydrogen atoms are omitted. Symmetry codes: $\mathrm{i}=-x, 1-y,-z ; \mathrm{j}=x+1, y, z ; \mathrm{k}$ $=x-1, y, z$. Bottom: packing showing the alternate layers along the $c$ axis. 
$\left[\left(\mathrm{UO}_{2}\right)_{2}(\mathrm{adac})_{2}(\mathrm{HCOOH})_{2}\right] \cdot \mathrm{CB} 6 \cdot 6 \mathrm{H}_{2} \mathrm{O}$ (2), in which formic acid results from $N, N$ dimethylformamide (DMF) hydrolysis, a frequent occurrence in solvo-hydrothermal syntheses. ${ }^{\left[{ }^{[g, h, j,}, 9 c\right]}$ The asymmetric unit in $\mathbf{2}$ contains one uranyl cation, one adac ${ }^{2-}$ ligand and half a centrosymmetric CB6 molecule (Figure 2). The uranyl ion is bound to one chelating carboxylate group, two oxygen atoms from two $\mu_{2}-\kappa^{1} O: \kappa^{1} O^{\prime}$-bridging carboxylate groups from two more ligands and a monodentate formic acid molecule [U-O(oxo) bond lengths 1.779(4) and 1.782(4)

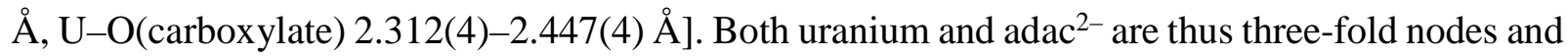
a ribbon-shaped 1D polymer parallel to the $a$ axis is formed, which is similar to that found in $\left[\mathrm{UO}_{2}(\right.$ adac) $(\mathrm{NMP})]\left(\mathrm{NMP}=N\right.$-methyl-2-pyrrolidone).$^{[9 \mathrm{c}]}$ The CB6 molecules are arranged into columns directed along the $b$ axis and, being uncomplexed, they are less distorted than in $\mathbf{1}$, with $\mathrm{O} \cdots \mathrm{O}$ distances between oxygen atoms facing one another across the portal of $6.903(7), 6.909(7)$ and 7.013(8) $\AA$. The uranyl-containing polymers and CB6 columns are arranged in alternate planar layers parallel to $\left(\begin{array}{lll}0 & 0 & 1\end{array}\right)$, an arrangement analogous to those found in other compounds involving uranyl carboxylates (and also terbium(III) adamantanedicarboxylate ${ }^{[3 \mathrm{r}]}$ ) and $\mathrm{CBs}_{.}{ }^{[\mathrm{g}, \mathrm{h}]}$ The hydrogen atom of the formic acid ligand forms a hydrogen bond with a lattice water molecule [O $\cdots \mathrm{O}$ distance $2.767(9) \AA, \mathrm{O}-\mathrm{H} \cdots \mathrm{O}$ angle $\left.146^{\circ}\right]$, and analysis of the Hirshfeld surface shows that weak $\mathrm{CH} \cdots \mathrm{O}$ hydrogen bonds ${ }^{[15]}$ link the $\mathrm{CB} 6$ molecule and the uranyl complex subunit, with $\mathrm{H} \cdots \mathrm{O}$ distances as short as $2.31 \AA$ for that involving the uncoordinated formic acid atom O8.

A heterometallic complex containing uranyl and potassium cations was obtained with the methanedisulfonate dianion, $\left[\left(\mathrm{UO}_{2}\right)_{2} \mathrm{~K}_{2}(\mathrm{CB} 6)(\mathrm{mds})_{2}(\mathrm{OH})_{2}\left(\mathrm{H}_{2} \mathrm{O}\right)_{8}\right] \cdot 4 \mathrm{H}_{2} \mathrm{O}(3)$. The asymmetric unit contains one of each metal cation, one mds ${ }^{2-}$ ligand and half a centrosymmetric CB6 molecule (Figure 3). The uranyl cation is chelated by two sulfonate groups from one ligand and is also bound 

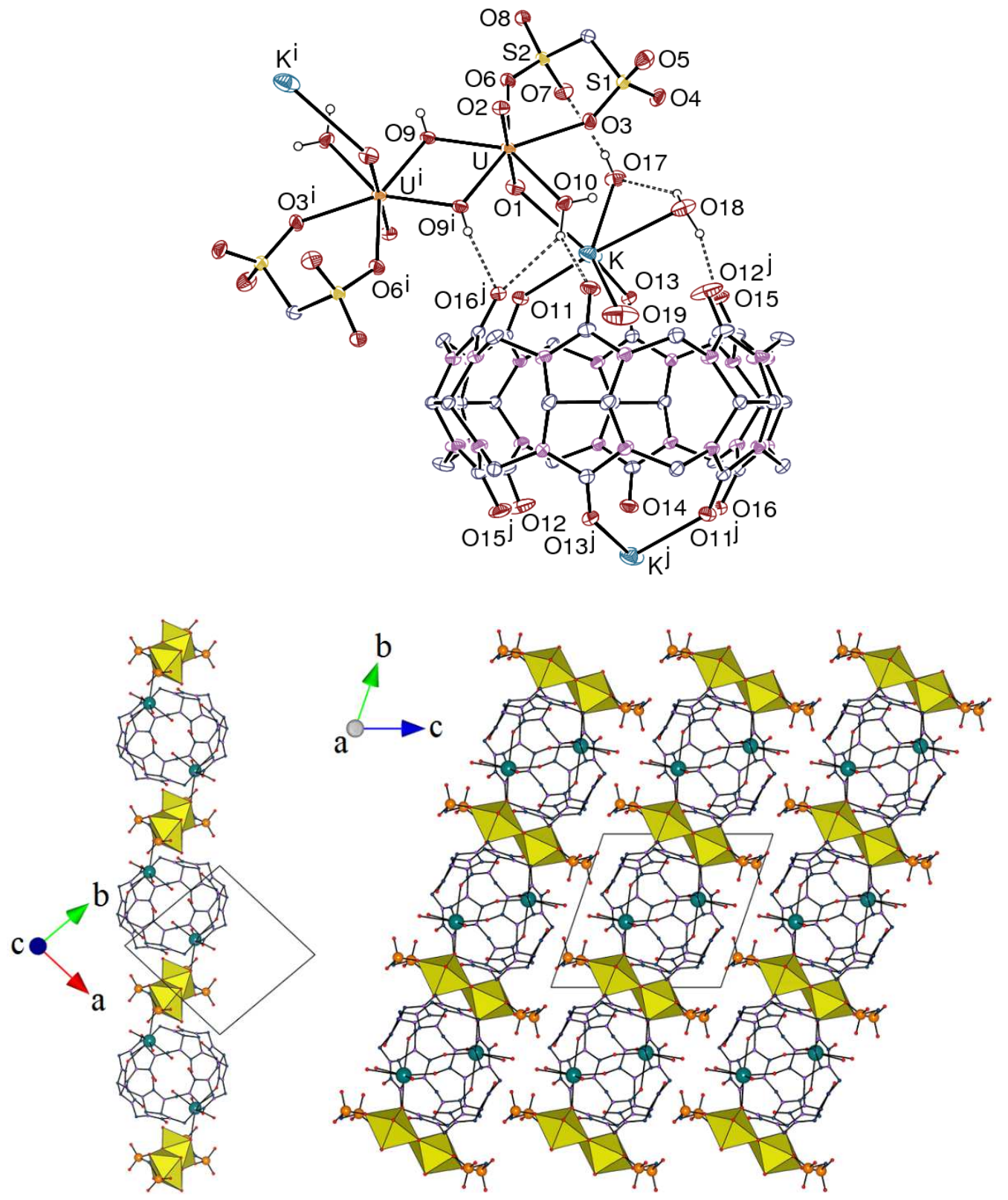

Figure 3. Top: view of compound 3. Displacement ellipsoids are drawn at the $30 \%$ probability level. The solvent molecules and the carbon-bound hydrogen atoms are omitted. Hydrogen bonds are shown as dashed lines. Symmetry codes: $\mathrm{i}=1-x,-y, 1-z ; \mathrm{j}=-x, 1-y, 1-z$. Bottom: views of the $1 \mathrm{D}$ polymer (left) and the packing (right); the uranium coordination polyhedra are colored yellow and potassium atoms are shown as blue spheres, solvent molecules and hydrogen atoms are omitted. 
to one water molecule and two bridging hydroxide groups, the latter generating a centrosymmetric uranyl dimer. The $\mathrm{U}-\mathrm{O}$ (oxo) bond lengths of 1.773(3) and 1.777(3) $\AA$ are unexceptional, as well as the U-O(sulfonate) bond lengths of 2.393(3) and 2.413(3) $\AA$ [average 2.40(4) $\AA$ for uranylsulfonate bonds reported in the CSD]. The $\left\{\left[\mathrm{UO}_{2}(\mathrm{OH})\right]_{2}\right\}^{2+}$ motif is a frequent one, with 42 examples reported in the CSD, and the U-O bond lengths of 2.319(3) and 2.337(3) $\AA$ and U-O-U angle of $109.59(11)^{\circ}$ match the average values from the literature [2.34(4) $\AA$ and $\left.111(3)^{\circ}\right]$. In contrast to compound $\mathbf{1}$, only one potassium cation is bound to two carbonyl groups at each CB6 portal, with however not very different $\mathrm{K}-\mathrm{O}$ bond lengths [2.576(3) and 2.768(5) $\mathrm{A}]$. The resulting ellipsoidal distorsion of CB6 is intermediate between those in $\mathbf{1}$ and $\mathbf{2}$, with $\mathrm{O} \cdots \mathrm{O}$ distances between oxygen atoms facing one another across the portal of 6.556(5), 6.934(7) and 7.056(6) $\AA$. Three water molecules, at 2.659(5)-3.001(5) $\AA$ are also bound to potassium, which is also involved in oxo bonding to uranyl, with a $\mathrm{K}-\mathrm{O} 1$ bond length of 2.934(4) $\AA$ that is at the upper end of the range of 2.58-3.08 $\AA$ [average 2.76(10) $\AA$ ] in the 26 similar cases reported in the CSD (some of them involving $\mathrm{U}^{\mathrm{V}}$ instead of $\mathrm{U}^{\mathrm{VI}}$ ). Although there is no obvious lengthening of the $\mathrm{U}=\mathrm{O} 1$ bond length, which would indicate that the $\mathrm{K}-\mathrm{O} 1$ bond is weak at best, this interaction appears prominently in the Hirshfeld surface (Figure 4). The presence of this oxo bonding and the dimeric nature of the uranyl complex subunit give rise to the formation of a $1 \mathrm{D}$ polymer parallel to [1 $\overline{1} 0]$. The hydroxide anion is involved in an intra-chain hydrogen bond with a carbonyl group [O $\cdots$ O distance 2.702(4) $\AA$, $\mathrm{O}-\mathrm{H} \cdots \mathrm{O}$ angle $170^{\circ}$ ], as well as the water molecule bound to uranyl (one of the bonds in this case being mediated by a lattice water molecule); one of the water ligands bound to potassium is directed toward the CB6 cavity (O19) and, although its hydrogen atoms have not been found, short $\mathrm{O} \cdots \mathrm{O}$ contacts of $3.00-3.27 \AA$ indicate that it is probably hydrogen bonded to carbonyl oxygen atoms; the other two water molecules bound to potassium are involved in three intra-chain 
hydrogen bonds and, in the case of O17, one inter-chain one [O ‥O distances 2.759(5)-2.933(5) $\AA$, $\mathrm{O}-\mathrm{H} \cdots \mathrm{O}$ angles $\left.123-170^{\circ}\right]$.

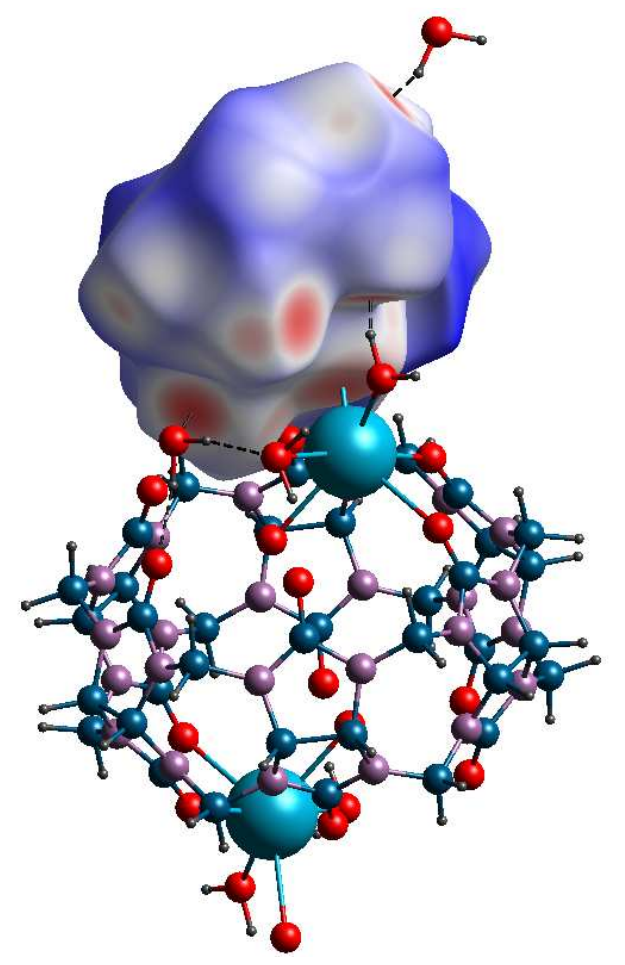

Figure 4. Hirshfeld surface mapped with $d_{\text {norm }}$ of the anionic subunit in complex $\mathbf{3}$, showing the oxo bonding interaction of the potassium cation (blue sphere). The hydrogen bonds made by water molecules are shown as dashed lines. The contacts shorter than the van der Waals separation appear as red spots on the surface, the two prominent ones at the forefront corresponding to $\mathrm{OH} \cdots \mathrm{O}$ (right) and $\mathrm{CH} \cdots \mathrm{O}$ (left) hydrogen bonds with neighbouring units (not represented).

The compound $\left[\left(\mathrm{UO}_{2}\right)_{2} \mathrm{Ce}_{2}(\mathrm{CB} 6)\left(\mathrm{C}_{2} \mathrm{O}_{4}\right)_{3}\left(\mathrm{NO}_{3}\right)_{4}\left(\mathrm{H}_{2} \mathrm{O}\right)_{6}\right] \cdot 2 \mathrm{H}_{2} \mathrm{O}$ (4) contains oxalate anions formed in situ, a common occurrence in complexes synthesized by hydrothermal methods, ${ }^{[1 \mathrm{a}, \mathrm{b}, 16]}$ the corresponding formation pathway having however been elucidated only in some particular cases. ${ }^{[17]}$ The asymmetric unit in $\mathbf{4}$ contains two uranyl and two cerium(III) cations, three oxalate anions (including two halves of centrosymmetric ones), four nitrate anions and one complete CB6 
molecule (Figure 5). The two uranyl atoms are chelated by one nitrate and two oxalate anions [U-

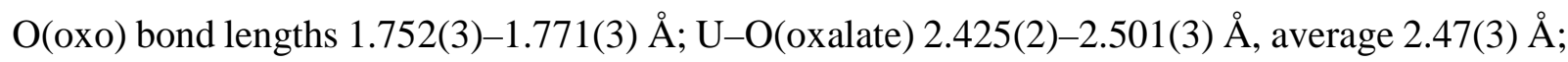
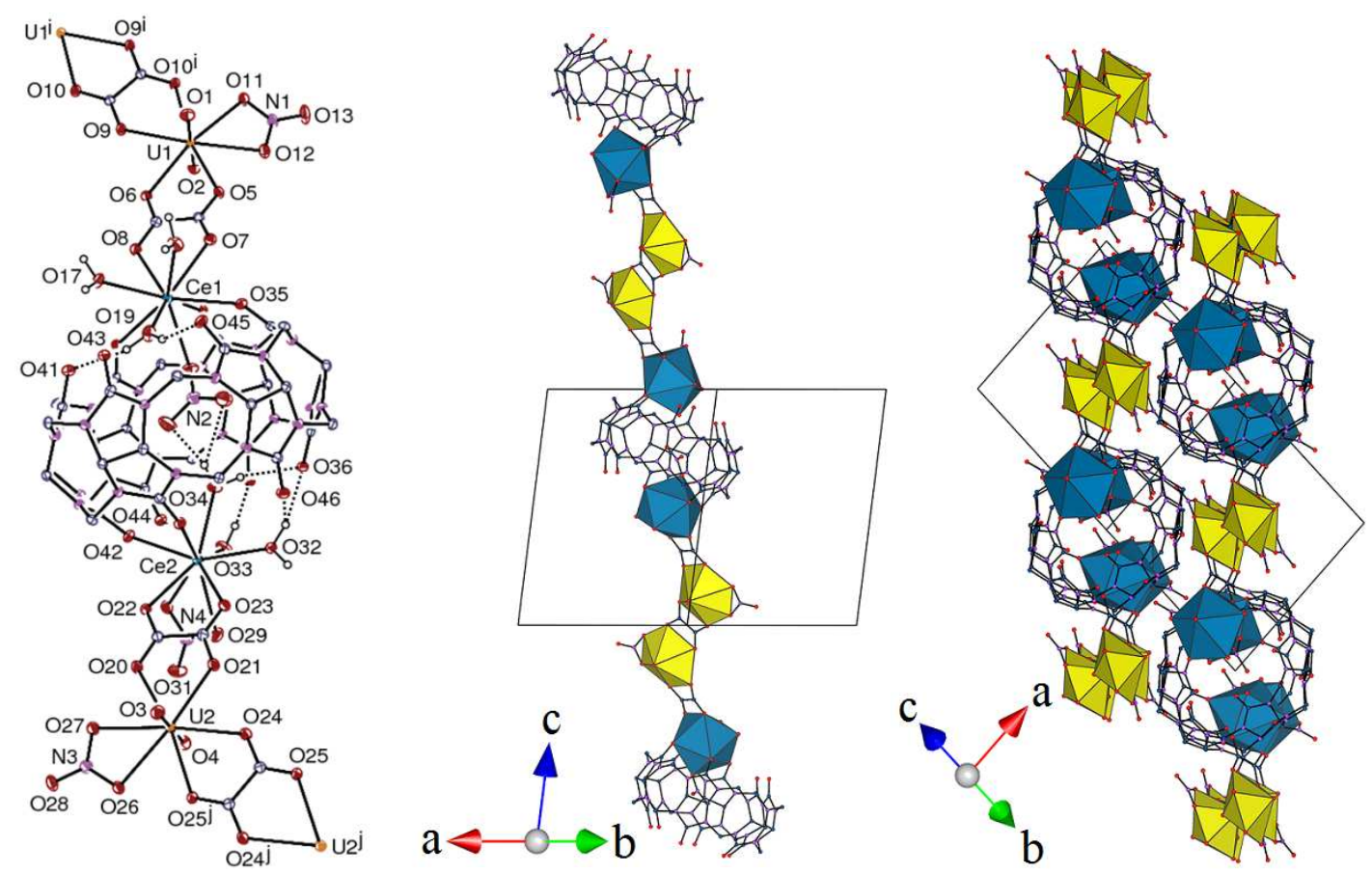

Figure 5. Left: view of compound 4. Displacement ellipsoids are drawn at the $30 \%$ probability level. The solvent molecules and the carbon-bound hydrogen atoms are omitted. Hydrogen bonds are shown as dashed lines. Symmetry codes: $\mathrm{i}=1-x, 1-y, 2-z ; \mathrm{j}=-x-1,-y,-z-1$. Middle: view of the $1 \mathrm{D}$ polymer. Right: view of the packing. The uranium coordination polyhedra are colored yellow and those of cerium blue, solvent molecules and hydrogen atoms are omitted in the last two views.

U-O(nitrate) 2.518(3)-2.558(3) A, average 2.536(15) $\AA$; the last two ranges are in agreement with the average values for similar motifs in the CSD, 2.45(4) and 2.52(4) $\AA$, respectively]. The centrosymmetric oxalate ligands ensure the formation of uranyl dimers, while the other oxalate anions bridge uranium and cerium cations. The two independent $\mathrm{Ce}^{\mathrm{III}}$ centres are in slightly different environments since, apart from one chelating oxalate and three water molecules which are common to both, $\mathrm{Ce} 1$ is bound to three carbonyl groups from $\mathrm{CB} 6$ and one monodentate nitrate anion, while $\mathrm{Ce} 2$ is bound to two carbonyl groups and one chelating nitrate. In both cases, the nine- 
coordinate environment is capped square antiprismatic, with atoms O14 (nitrate) and O34 (water) in the capping positions. The Ce-O(carbonyl) bond lengths of 2.440(2)-2.656(2) A fall within the large range measured for Ce bond lengths to CB6, 2.40-2.75 $\AA^{[3 a, g, j, k, t]}$ The $\mathrm{Ce}-\mathrm{O}$ (oxalate) bond lengths of 2.537(3)-2.568(3) $\AA$ [average 2.552(12) $\AA$ ] match the average value of 2.55(5) $\AA$ from the CSD. As expected, the $\mathrm{Ce}-\mathrm{O}$ (nitrate) bond length is shorter for the monodentate group [2.496(3) $\AA$ ] than for the chelating one [2.609(3) and 2.673(3) $\mathrm{A}]$, both being in agreement with the average values for similar cases in the CSD, 2.50(7) and 2.62(7) $\AA$, respectively. The CeO(water) bond lengths span the range 2.457(3)-2.569(3) $\AA$ [average 2.50(4) $\AA$, to be compared to 2.53(6) $\AA$ from the CSD]. Coordination of two lanthanide cations, one at each portal of CB5, CB6, CB7 or their derivatives, resulting in the formation of polymeric chains, is frequently observed, as are also chains with two bridging lanthanide cations at each portal. ${ }^{[1 \mathrm{j}, 3 \mathrm{~g}, \mathrm{l}, \mathrm{n}, 18]} \mathrm{A} 1 \mathrm{D}$ polymer running along the [ $\left.\begin{array}{lll}2 & 1 & 3\end{array}\right]$ axis is formed here also, but the originality of the present structure arises from the incorporation of uranyl oxalate dimers into the chains, which act as spacers for $\mathrm{Ce}_{2}(\mathrm{CB} 6)^{6+}$ units. It has been shown that, in the presence of perrhenate anions, uranyl-lanthanide heterometallic complexes with CB6 could be obtained, in which both cations are bound to carbonyl groups ${ }^{[5 c]}$ and also that, in the presence of 1,2-ethanedisulfonate, only the lanthanide cation is coordinated to CB6, uranyl being bound to sulfonate, hydroxide and water ligands. ${ }^{[5 k]}$ Compound 4 shows that the same trend is found when a dicarboxylate ligand is present, with uranyl preferentially bound to carboxylates, and $\mathrm{Ce}$ III to $\mathrm{CB} 6$ (with additional bonding to carboxylates). The chains are stacked in a bump-to-hollow fashion, as expected from the bulkiness of CB6. The monodentate nitrate anion bound to $\mathrm{Ce} 1$ and one of the water molecules bound to $\mathrm{Ce} 2$ are included in the $\mathrm{CB} 6$ cavity, the water molecule being involved in an asymmetric, bifurcated hydrogen bond with the two

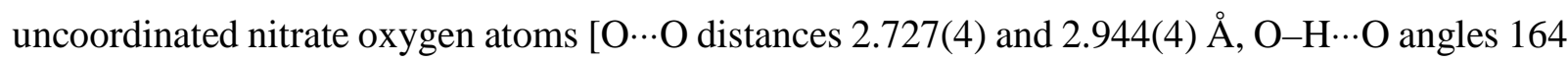


and $\left.134^{\circ}\right]$, and another one with a carbonyl group [3.027(4) $\left.\AA, 160^{\circ}\right]$. The position of the nitrate group in the CB6 cavity is probably determined in a large measure by hydrogen bonding to the water ligand, the stronger component of the bifurcated bond being with atom O15. Inclusion of coordinated or free anions in CBs is common and has been reported for nitrate, ${ }^{[3 \mathrm{~d}, \mathrm{j}, 5 \mathrm{k}]}$ and also for species as diverse as chloride, ${ }^{[3 c, d, 4 a]}$ acetate, ${ }^{[1 d]}$ isonicotinate $^{[3 e, f]}$ or perrhenate ${ }^{[3 \mathrm{~g}, 4 \mathrm{~b}, 5 \mathrm{c}]}$ The coordinated nitrate atom $\mathrm{O} 14$ (and also to a lesser extent the uncoordinated atom O16) makes several contacts with oxygen, nitrogen and carbon atoms of CB6, in the range 2.7-3.4 $\AA$, the shortest being with a ureido carbon atom at 2.717(5) $\AA$ [2.915(5) $\AA$ in the case of O16], which is in keeping with the fact that, although the cavity lining of CBs is overall negatively charged, ${ }^{[1 b]}$ the bonding of ureido carbon atoms to three electron-withdrawing atoms makes them slightly electropositive, ${ }^{[1 \mathrm{f}]}$ an effect which may be reinforced by carbonyl groups coordination. ${ }^{[3 c, \mathrm{~d}, 19]}$ These shortest contacts made by $\mathrm{O} 14$ and $\mathrm{O} 16$ with ureido carbon atoms are well apparent on the Hirshfeld surface of the nitrate anion (Figure 6), which confirms their significance. The CB6 molecule presents an ellipsoidal distorsion larger than that in compounds $\mathbf{1}-\mathbf{3}$, with $\mathrm{O} \cdots \mathrm{O}$ distances between oxygen atoms facing one another across the portal in the range of 6.198(4)-7.796(4) $\AA$. An intricate network of hydrogen bonds involving the coordinated and free water molecules as donors and uranyl, nitrate, carboxylate, carbonyl and water oxygen atoms as acceptors unites the chains into a 3D assembly. 


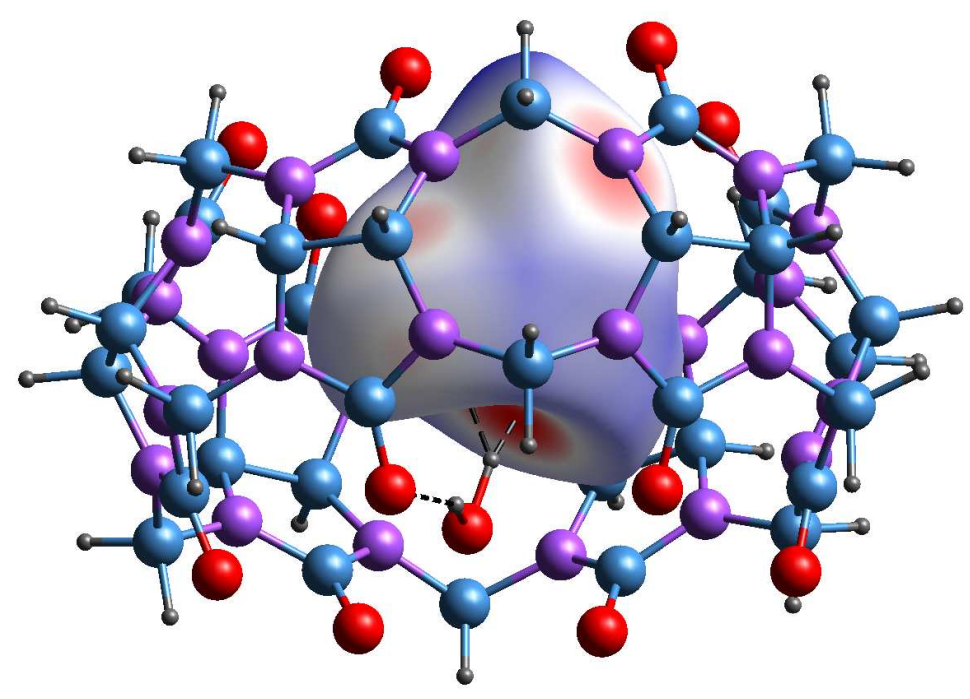

Figure 6. Hirshfeld surface mapped with $d_{\text {norm }}$ of the included nitrate anion in complex 4 . The hydrogen bonds made by the included water molecule are shown as dashed lines. The contacts shorter than the van der Waals separation appear as red spots on the surface and correspond to the hydrogen bond and the contacts between O14 (right) and O16 (left) with ureido carbon atoms. The bump at the top of the Hirshfeld surface is due to removal of the coordinated cerium atom.

\section{Conclusions}

Previous work has shown that combining cucurbiturils and carboxylic, sulfonic or mineral acids as ligands for uranyl cations provides complexes displaying original and varied structures, with either all components involved in the building of a single complex unit, often multi-dimensional, or formation of separate subunits in the cases in which no direct bonding of uranyl to the macrocycle occurs. ${ }^{[5 b-1]}$ The four complexes reported herein, which all involve CB6, constitute an extension of this work to three carboxylates, oxalate, 1,3-adamantanedicarboxylate and 1,3adamantanediacetate, and the simplest of disulfonates, methanedisulfonate. In no case is there any direct bonding of uranyl to CB6, the latter being bound instead to potassium or cerium cations when present. Complex 1, with 1,3-adamantanedicarboxylate, displays columns of uranyl 
dicarboxylate chains and potassium-CB6 chains running side-by-side and associated to one another through bridging nitrate anions, in which a remarkable feature is the perfect match in length of the repeat units of both chains, resulting in two uranyl-containing strands surrounding each CB6 column as scaffolding. This pattern is disrupted with 1,3-adamantanediacetate in complex $\mathbf{2}$, due not only to the absence of potassium ions but also to the longer size of the carboxylate ligand which would not enable the match in length between the two subunits. Instead, 1D uranyl-containing polymers associate with columns of CB6 molecules to form a layered arrangement. In the case of methanedisulfonate (complex 3), CB6-di-potassium cations are linked to one another by uranyl dimers containing hydroxide bridges and chelating sulfonate ligands, the connection between the subunits being solely through potassium oxo-bonding to uranyl. Complex $\mathbf{4}$ is a heterometallic complex containing uranyl and cerium(III) cations, in which 1D polymerization arises from the presence of oxalate anions formed in situ. As in previous cases of uranyl-lanthanide heterometallic complexes with sulfonate anions and CB6 molecules, ${ }^{[5 \mathrm{k}]}$ the macrocycle preferentially coordinates to the lanthanide cation, the uranyl cation being chelated by one nitrate and two oxalate ligands. One nitrate anion and one water molecule, bound to different $\mathrm{Ce}^{\mathrm{III}}$ ions and hydrogen bonded to each other, are included in the CB6 cavity, an arrangement which may involve interactions between two nitrate oxygen atoms and slightly electropositive ureido carbon atoms.

\section{Experimental Section}

General: $\mathrm{UO}_{2}\left(\mathrm{NO}_{3}\right)_{2} \cdot 6 \mathrm{H}_{2} \mathrm{O}$ (depleted uranium, R. P. Normapur, 99\%), $\mathrm{KNO}_{3}$, and $\mathrm{Ce}\left(\mathrm{NO}_{3}\right)_{3} \cdot 6 \mathrm{H}_{2} \mathrm{O}$ were purchased from Prolabo, cucurbit[6]uril pentahydrate was from Fluka, 1,3adamantanedicarboxylic acid, 1,3-adamantanediacetic acid and the di-potassium salt of methanedisulfonic acid were from Aldrich. Elemental analyses of the crystals could not be 
conducted since in all cases their formation was accompanied by the presence of insoluble remnants of cucurbit[6]uril and/or the deposition of amorphous precipitates.

Caution! Uranium is a radioactive and chemically toxic element, and uranium-containing samples must be handled with suitable care and protection.

$\left[\left(\mathbf{U O}_{2}\right)_{2} \mathbf{K}_{2}(\mathbf{C B 6})(\mathbf{a d c})_{2}\left(\mathbf{N O}_{3}\right)_{2}\left(\mathbf{H}_{2} \mathbf{O}\right)_{2}\right] \cdot 5 \mathrm{H}_{2} \mathrm{O}(\mathbf{1}): \mathrm{CB} 6 \cdot 5 \mathrm{H}_{2} \mathrm{O}(11 \mathrm{mg}, 0.01 \mathrm{mmol}), \mathrm{H}_{2} \mathrm{adc}(11 \mathrm{mg}$, $0.05 \mathrm{mmol}), \mathrm{UO}_{2}\left(\mathrm{NO}_{3}\right)_{2} \cdot 6 \mathrm{H}_{2} \mathrm{O}(50 \mathrm{mg}, 0.10 \mathrm{mmol}), \mathrm{KNO}_{3}(20 \mathrm{mg}, 0.20 \mathrm{mmol})$, and demineralized water $(0.8 \mathrm{~mL})$ were placed in a $15 \mathrm{~mL}$ tightly closed glass vessel and heated at $140{ }^{\circ} \mathrm{C}$ under autogenous pressure, giving light yellow crystals of complex $\mathbf{1}$ in low yield within two weeks.

$\left[\left(\mathbf{U O}_{2}\right)_{\mathbf{2}}(\mathbf{a d a c})_{\mathbf{2}}(\mathbf{H C O O H})_{2}\right] \cdot \mathbf{C B 6} \cdot \mathbf{6 H} \mathrm{H}_{\mathbf{2}} \mathrm{O}(\mathbf{2}): \mathbf{C B} 6 \cdot 5 \mathrm{H}_{2} \mathrm{O}(11 \mathrm{mg}, 0.01 \mathrm{mmol}), \mathrm{H}_{2} \operatorname{adac}(13 \mathrm{mg}, 0.05$ mmol), $\mathrm{UO}_{2}\left(\mathrm{NO}_{3}\right)_{2} \cdot 6 \mathrm{H}_{2} \mathrm{O}(25 \mathrm{mg}, 0.05 \mathrm{mmol}), \quad N, N$-dimethylformamide $(0.3 \mathrm{~mL})$, and demineralized water $(1.0 \mathrm{~mL})$ were placed in a $15 \mathrm{~mL}$ tightly closed glass vessel and heated at 140 ${ }^{\circ} \mathrm{C}$ under autogenous pressure, giving light yellow crystals of complex $\mathbf{2}$ in low yield within two weeks.

$\left[\left(\mathbf{U O}_{2}\right)_{2} \mathbf{K}_{2}(\mathbf{C B 6})(\mathbf{m d s})_{2}(\mathbf{O H})_{2}\left(\mathbf{H}_{2} \mathbf{O}\right)_{\mathbf{8}}\right] \cdot \mathbf{4} \mathbf{H}_{2} \mathrm{O}(3): \mathrm{CB} 6 \cdot 5 \mathrm{H}_{2} \mathrm{O}(11 \mathrm{mg}, 0.01 \mathrm{mmol}), \mathrm{K}_{2} \mathrm{mds}(25 \mathrm{mg}$, $0.10 \mathrm{mmol}), \mathrm{UO}_{2}\left(\mathrm{NO}_{3}\right)_{2} \cdot 6 \mathrm{H}_{2} \mathrm{O}(50 \mathrm{mg}, 0.10 \mathrm{mmol})$, and demineralized water $(1.5 \mathrm{~mL})$ were placed in a $15 \mathrm{~mL}$ tightly closed glass vessel and heated at $180{ }^{\circ} \mathrm{C}$ under autogenous pressure, giving light yellow crystals of complex $\mathbf{3}$ in low yield within one week. 
$\left[\left(\mathbf{U O}_{2}\right)_{2} \mathrm{Ce}_{2}(\mathbf{C B 6})\left(\mathbf{C}_{2} \mathbf{O}_{4}\right)_{3}\left(\mathbf{N O}_{3}\right)_{4}\left(\mathbf{H}_{2} \mathbf{O}\right)_{6}\right] \cdot 2 \mathbf{H}_{2} \mathrm{O} \quad(\mathbf{4}): \quad \mathrm{CB} 6 \cdot 5 \mathrm{H}_{2} \mathrm{O} \quad(11 \mathrm{mg}, \quad 0.01 \mathrm{mmol}), \quad \alpha-$ cyclodextrin (20 mg, $0.02 \mathrm{mmol}), \mathrm{UO}_{2}\left(\mathrm{NO}_{3}\right)_{2} \cdot 6 \mathrm{H}_{2} \mathrm{O}(50 \mathrm{mg}, 0.10 \mathrm{mmol}), \mathrm{Ce}\left(\mathrm{NO}_{3}\right)_{3} \cdot 6 \mathrm{H}_{2} \mathrm{O}(43 \mathrm{mg}$, $0.10 \mathrm{mmol})$, and demineralized water $(1.5 \mathrm{~mL})$ were placed in a $15 \mathrm{~mL}$ tightly closed glass vessel and heated at $140{ }^{\circ} \mathrm{C}$ under autogenous pressure, giving light yellow crystals of complex 4 in low yield within one month.

Crystallography: The data were collected at 150(2) K on a Nonius Kappa-CCD area detector diffractometer $^{[20]}$ using graphite-monochromated Mo K $\alpha$ radiation $(\lambda=0.71073 \AA)$. The crystals were introduced into glass capillaries with a protective coating of Paratone-N oil (Hampton Research). The unit cell parameters were determined from ten frames, then refined on all data. The data (combinations of $\varphi$ - and $\omega$-scans with a minimum redundancy of 4 for $90 \%$ of the reflections) were processed with HKL2000. ${ }^{[21]}$ Absorption effects were corrected empirically with the program SCALEPACK. ${ }^{[21]}$ The structures were solved either by Patterson map interpretation (3) or direct methods (4) with SHELXS, ${ }^{[22]}$ or by intrinsic phasing with $\operatorname{SHELXT}^{[23]}$ (1 and $\left.\mathbf{2}\right)$, expanded by subsequent difference Fourier synthesis and refined by full-matrix least-squares on $F^{2}$ with SHELXL. ${ }^{[22]}$ All non-hydrogen atoms were refined with anisotropic displacement parameters. In compound $\mathbf{1}$, one water molecule $(\mathrm{O} 18)$ is disordered over two positions which were refined with occupancy parameters constrained to sum to unity, and another one (O19) was given an occupancy factor of 0.5 in order to retain an acceptable displacement parameter. The hydrogen atom of the carboxylic group in $\mathbf{2}$, that of the hydroxyl group in $\mathbf{3}$ and, when possible, the hydrogen atoms bound to water oxygen atoms were retrieved from difference Fourier maps (some of them were not found for 1, 2 and 3), and the carbon-bound hydrogen atoms were introduced at calculated positions; all hydrogen atoms were treated as riding atoms with an isotropic displacement 
parameter equal to 1.2 times that of the parent atom. Some voids in the lattices of $\mathbf{1}$ and $\mathbf{2}$ likely indicate the presence of other, unresolved water solvent molecules. Crystal data and structure refinement parameters are given in Table 1 . The molecular plots were drawn with ORTEP-3 ${ }^{[24]}$ and the packings with VESTA. ${ }^{[25]}$

CCDC-1538211-1538214 contain the supplementary crystallographic data for this paper. These data can be obtained free of charge from The Cambridge Crystallographic Data Centre via www.ccdc.cam.ac.uk/data request/cif.

Table 1 Crystal data and structure refinement details

\begin{tabular}{|c|c|c|c|c|}
\hline & 1 & 2 & 3 & 4 \\
\hline Empirical formula & $\mathrm{C}_{60} \mathrm{H}_{78} \mathrm{~K}_{2} \mathrm{~N}_{26} \mathrm{O}_{37} \mathrm{U}_{2}$ & $\mathrm{C}_{66} \mathrm{H}_{88} \mathrm{~N}_{24} \mathrm{O}_{34} \mathrm{U}_{2}$ & $\mathrm{C}_{38} \mathrm{H}_{66} \mathrm{~K}_{2} \mathrm{~N}_{24} \mathrm{O}_{42} \mathrm{~S}_{4} \mathrm{U}_{2}$ & $\mathrm{C}_{42} \mathrm{H}_{52} \mathrm{Ce}_{2} \mathrm{~N}_{28} \mathrm{O}_{48} \mathrm{U}_{2}$ \\
\hline$M\left(\mathrm{~g} \mathrm{~mol}^{-1}\right)$ & 2309.74 & 2237.66 & 2213.65 & 2473.42 \\
\hline Crystal system & triclinic & triclinic & triclinic & triclinic \\
\hline Space group & $P_{1}$ & $P_{\overline{1}}$ & $P \overline{1}$ & $P \overline{1}$ \\
\hline$a(\AA)$ & $9.9856(5)$ & $11.8996(5)$ & $12.1522(4)$ & $13.1138(5)$ \\
\hline$b(\AA)$ & $12.8984(7)$ & $12.3665(3)$ & $12.2334(5)$ & $16.6700(7)$ \\
\hline$c(\AA)$ & $17.0795(9)$ & $17.2789(8)$ & $12.7639(4)$ & $16.7399(7)$ \\
\hline$\alpha\left(^{\circ}\right)$ & $77.465(2)$ & $97.615(3)$ & $70.510(2)$ & $91.081(2)$ \\
\hline$\beta\left(^{\circ}\right)$ & $83.433(3)$ & $101.055(2)$ & $83.939(2)$ & $100.123(2)$ \\
\hline$\gamma\left(\left(^{\circ}\right)\right.$ & $67.842(3)$ & $118.017(2)$ & $81.505(2)$ & $109.057(2)$ \\
\hline$V\left(\AA^{3}\right)$ & 1987.50(19) & $2129.12(16)$ & $1765.93(11)$ & $3393.6(2)$ \\
\hline$Z$ & 1 & 1 & 1 & 2 \\
\hline$\rho_{\text {calcd }}\left(\mathrm{g} \mathrm{cm}^{-3}\right)$ & 1.930 & 1.745 & 2.082 & 2.421 \\
\hline$\mu\left(\mathrm{Mo}-\mathrm{K}_{\alpha}\right)\left(\mathrm{mm}^{-1}\right)$ & 4.284 & 3.898 & 4.935 & 6.213 \\
\hline$F(000)$ & 1138 & 1108 & 1084 & 2368 \\
\hline Reflections collected & 115449 & 122240 & 100537 & 216173 \\
\hline Independent reflections & 7543 & 8089 & 9110 & 20695 \\
\hline Observed reflections $[I>2 \sigma(I)]$ & 6964 & 7524 & 8530 & 16532 \\
\hline$R_{\text {int }}$ & 0.032 & 0.045 & 0.064 & 0.063 \\
\hline Parameters refined & 587 & 568 & 505 & 1099 \\
\hline$R_{1}$ & 0.035 & 0.039 & 0.039 & 0.033 \\
\hline $\mathrm{w} R_{2}$ & 0.096 & 0.102 & 0.107 & 0.078 \\
\hline$S$ & 1.115 & 1.198 & 1.045 & 1.033 \\
\hline$\Delta \rho_{\min }\left(\mathrm{e} \AA^{-3}\right)$ & -1.08 & -1.26 & -2.56 & -2.18 \\
\hline$\Delta \rho_{\max }\left(\mathrm{e} \AA^{-3}\right)$ & 2.85 & 2.20 & 3.00 & 1.71 \\
\hline
\end{tabular}




\section{References}

[1] a) W. A. Freeman, W. L. Mock, N. Y. Shih, J. Am. Chem. Soc. 1981, 103, 7367-7368; b) J. W. Lee, S. Samal, N. Selvapalam, H. J. Kim, K. Kim, Acc. Chem. Res. 2003, 36, 621630; c) J. Lagona, P. Mukhopadhyay, S. Chakrabarti, L. Isaacs, Angew. Chem., Int. Ed. 2005, 44, 4844-4870; d) H. Cong, Q. J. Zhu, S. F. Xue, Z. Tao, G. Wei, Chinese Sci. Bull. 2010, 55, 3633-3640; e) W. M. Nau, M. Florea, K. I. Assaf, Isr. J. Chem. 2011, 51, 559577; f) D. Bardelang, K. A. Udachin, D. M. Leek, J. C. Margeson, G. Chan, C. I. Ratcliffe, J. A. Ripmeester, Cryst. Growth Des. 2011, 11, 5598-5614; g) E. Masson, X. Ling, R. Joseph, L. Kyeremeh-Mensah, X. Lu, RSC Adv. 2012, 2, 1213-1247; h) J. Lü, J. X. Lin, M. N. Cao, R. Cao, Coord. Chem. Rev. 2013, 257, 1334-1356; i) X. L. Ni, X. Xiao, H. Cong, L. L. Liang, K. Cheng, X. J. Cheng, N. N. Ji, Q. J. Zhu, S. F. Xue, Z. Tao, Chem. Soc. Rev. 2013, 42, 9480-9508; j) X. L. Ni, S. F. Xue, Z. Tao, Q. J. Zhu, L. F. Lindoy, G. Wei, Coord. Chem. Rev. 2015, 287, 89-113; k) K. I. Assaf, W. M. Nau, Chem. Soc. Rev. 2015, 44, 394 418.

[2] a) M. Sundararajan, V. Sinha, T. Bandyopadhyay, S. K. Ghosh, J. Phys. Chem. A 2012, 116, 4388-4395; b) L. Shao, X. Wang, Y. Ren, S. Wang, J. Zhong, M. Chu, H. Tang, L. Luo, D. Xie, Chem. Eng. J. 2016, 286, 311-319.

[3] See, for example: a) D. G. Samsonenko, J. Lipkowski, O. A. Gerasko, A. V. Virovets, M. N. Sokolov, V. P. Fedin, J. G. Platas, R. Hernandez-Molina, A. Mederos, Eur. J. Inorg. Chem. 2002, 2380-2388; b) O. A. Gerasko, M. N. Sokolov, V. P. Fedin, Pure Appl. Chem. 2004, 76, 1633-1646; c) J. X. Liu, L. S. Long, R. B. Huang, L. S. Zheng, Cryst. Growth Des. 2006, 6, 2611-2614; d) J. X. Liu, L. S. Long, R. B. Huang, L. S. Zheng, Inorg. Chem. 2007, 46, 10168-10173; e) O. A. Gerasko, E. A. Mainicheva, M. I. Naumova, O. P. 
Yurjeva, A. Alberola, C. Vicent, R. Llusar, V. P. Fedin, Eur. J. Inorg. Chem. 2008, 416424; f) O. A. Gerasko, E. A. Mainicheva, M. I. Naumova, M. Neumaier, M. M. Kappes, S. Lebedkin, D. Fenske, V. P. Fedin, Inorg. Chem. 2008, 47, 8869-8880; g) P. Thuéry, Inorg. Chem. 2009, 48, 4497-4513; h) P. Thuéry, Inorg. Chem. 2010, 49, 9078-9085; i) P. Thuéry, Inorg. Chem. 2011, 50, 10558-10560; j) P. Thuéry, Cryst. Growth Des. 2012, 12, 16321640; k) P. Thuéry, CrystEngComm 2012, 14, 8128-8136; 1) L. L. Liang, Y. Zhao, Y. Q. Zhang, Z. Tao, S. F. Xue, Q. J. Zhu, J. X. Liu, CrystEngComm 2013, 15, 3943-3950; m) X. J. Cheng, L. L. Liang, K. Chen, N. N. Ji, X. Xiao, J. X. Zhang, Y. Q. Zhang, S. F. Xue, Q. J. Zhu, X. L. Ni, Z. Tao, Angew. Chem. Int. Ed. 2013, 52, 7252-7255; n) Y. Zhao, L. L. Liang, K. Chen, T. Zhang, X. Xiao, Y. Q. Zhang, Z. Tao, S. F. Xue, Q. J. Zhu, CrystEngComm 2013, 15, 7987-7998; o) M. Ren, D. Pinkowicz, M. Yoon, K. Kim, L. M. Zheng, B. K. Breedlove, M. Yamashita, Inorg. Chem. 2013, 52, 8342-8348; p) F. F. da Silva, C. A. F. de Oliveira, E. H. L. Falcão, J. Chojnacki, J. L. Nevesa, S. Alves Jr., Dalton Trans. 2014, 43, 5435-5442; q) J. J. Zhou, X. Yu, Y. C. Zhao, X. Xiao, Y. Q. Zhang, S. F. Xue, Z. Tao, J. X. Liu, Q. J. Zhu, CrystEngComm 2014, 16, 10674-10680; r) P. Thuéry, J. Solid State Chem. 2015, 227, 265-272; s) N. Rawat, A. Kar, A. Bhattacharyya, A. Rao, S. K. Nayak, C. Nayak, S. N. Jha, D. Bhattacharyya, B. S. Tomar, Dalton Trans. 2015, 44, 4246-4258; t) B. Yang, Z. Z. Gao, J. H. Lu, Q. J. Zhu, S. F. Xue, Z. Tao, T. J. Prior, C. Redshaw, G. Wei, X. Xiao, CrystEngComm 2016, 18, 5028-5035.

[4] a) D. G. Samsonenko, M. N. Sokolov, O. A. Gerasko, A. V. Virovets, J. Lipkowski, D. Fenske, V. P. Fedin, Russ. Chem. Bull., Int. Ed. 2003, 52, 2132-2139; b) P. Thuéry, Eur. J. Inorg. Chem. 2015, 2037-2040.

[5] a) O. A. Gerasko, D. G. Samsonenko, A. A. Sharonova, A. V. Virovets, J. Lipkowski, V. P. Fedin, Russ. Chem. Bull. 2002, 51, 346-349; b) P. Thuéry, Cryst. Growth Des. 2008, 8, 
4132-4143; c) P. Thuéry, Inorg. Chem. 2009, 48, 825-827; d) P. Thuéry, CrystEngComm 2009, 11, 1150-1156; e) P. Thuéry, Cryst. Growth Des. 2009, 9, 1208-1215; f) P. Thuéry, B. Masci, Cryst. Growth Des. 2010, 10, 716-725; g) P. Thuéry, Cryst. Growth Des. 2011, 11, 2606-2620; h) P. Thuéry, Cryst. Growth Des. 2011, 11, 3282-3294; i) P. Thuéry, Cryst. Growth Des. 2011, 11, 5702-5711; j) P. Thuéry, Cryst. Growth Des. 2012, 12, 499-507; k) P. Thuéry, CrystEngComm 2012, 14, 3363-3366; 1) P. Thuéry, J. Harrowfield, Eur. J. Inorg. Chem. 2017, 979-987.

[6] a) L. Mei, Q. Y. Wu, C. M. Liu, Y. L. Zhao, Z. F. Chai, W. Q. Shi, Chem. Commun. 2014, 50, 3612-3615; b) L. Mei, L. Wang, C. M. Liu, Y. L. Zhao, Z. F. Chai, W. Q. Shi, Chem. Eur. J. 2015, 21, 10226-10235; c) L. Mei, L. Wang, L. Y. Yuan, S. W. An, Y. L. Zhao, Z. F. Chai, P. C. Burns, W. Q. Shi, Chem. Commun. 2015, 51, 11990-11993; d) L. Mei, Z. N. Xie, K. Q. Hu, L. Wang, L. Y. Yuan, Z. J. Li, Z. F. Chai, W. Q. Shi, Dalton Trans. 2016, $45,13304-13307$.

[7] a) M. B. Andrews, C. L. Cahill, Chem. Rev. 2013, 113, 1121-1136; b) T. Loiseau, I. Mihalcea, N. Henry, C. Volkringer, Coord. Chem. Rev. 2014, 266-267, 69-109; c) J. Su, J. S. Chen, Struct. Bond. 2015, 163, 265-296.

[8] C. R. Groom, I. J. Bruno, M. P. Lightfoot, S. C. Ward, Acta Crystallogr., Sect. B 2016, 72, $171-179$.

[9] a) J. A. Rusanova, E. B. Rusanov, K. V. Domasevitch, Acta Crystallogr., Sect. C 2010, 66, m207-m210; b) P. Thuéry, E. Rivière, J. Harrowfield, Inorg. Chem. 2015, 54, 2838-2850; c) P. Thuéry, J. Harrowfield, CrystEng Comm 2015, 17, 4006-4018.

[10] a) P. Thuéry, CrystEngComm 2012, 14, 6369-6373; b) P. Thuéry, Inorg. Chem. 2013, 52, 435-447; c) P. Thuéry, CrystEngComm 2013, 15, 2401-2410; d) W. Yang, T. Tian, H. Y. 
Wu, Q. J. Pan, S. Dang, Z. M. Sun, Inorg. Chem. 2013, 52, 2736-2743; e) P. Thuéry, Eur. J. Inorg. Chem. 2014, 58-68.

[11] a) P. Thuéry, CrystEngComm 2008, 10, 1126-1128; b) P. Thuéry, CrystEngComm 2009, 11, 2319-2325; c) P. Thuéry, Cryst. Growth Des. 2010, 10, 2061-2063; d) P. L. Arnold, E. Hollis, F. J. White, N. Magnani, R. Caciuffo and J. B. Love, Angew. Chem., Int. Ed. 2011, 50, 887-890; e) J. Diwu, S. Wang, J. J. Good, V. H. DiStefano, T. E. Albrecht-Schmitt, Inorg. Chem. 2011, 50, 4842-4850; f) K. E. Knope, D. T. de Lill, C. E. Rowland, P. M. Cantos, A. de Bettencourt-Dias and C. L. Cahill, Inorg. Chem. 2012, 51, 201-206; g) C. Volkringer, N. Henry, S. Grandjean and T. Loiseau, J. Am. Chem. Soc. 2012, 134, 12751283; h) I. Mihalcea, C. Volkringer, N. Henry, T. Loiseau, Inorg. Chem. 2012, 51, 96109618; i) P. L. Arnold, E. Hollis, G. S. Nichol, J. B. Love, J. C. Griveau, R. Caciuffo, N. Magnani, L. Maron, L. Castro, A. Yahia, S. O. Odoh, G. Schreckenbach, J. Am. Chem. Soc. 2013, 135, 3841-3854; j) P. M. Cantos, S. J. A. Pope, C. L. Cahill, CrystEngComm 2013, 15, 9039-9051; k) Y. N. Hou, X. T. Xu, N. Xing, F. Y. Bai, S. B. Duan, Q. Sun, S. Y. Wei, Z. Shi, H. Z. Zhang, Y. H. Xing, ChemPlusChem 2014, 79, 1304-1315; 1) P. Thuéry, Cryst. Growth Des. 2014, 14, 2665-2676; m) P. Thuéry, J. Harrowfield, Inorg. Chem. 2015, 54, 6296-6305.

[12] J. Heo, J. Kim, D. Whang, K. Kim, Inorg. Chim. Acta 2000, 297, 307-312.

[13] M. A. Spackman, D. Jayatilaka, CrystEngComm 2009, 11, 19-32.

[14] S. K. Wolff, D. J. Grimwood, J. J. McKinnon, M. J. Turner, D. Jayatilaka, M. A. Spackman, CrystalExplorer 3.0, University of Western Australia, 2012.

[15] a) R. Taylor, O. Kennard, J. Am. Chem. Soc. 1982, 104, 5063-5070; b) G. R. Desiraju, Acc. Chem. Res. 1996, 29, 441-449. 
[16] See, for example: a) X. Li, R. Cao, D. Sun, Q. Shi, W. Bi, M. Hong, Inorg. Chem. Commun. 2003, 6, 815-818; b) M. Frisch, C. L. Cahill, Dalton Trans. 2005, 1518-1523; c) B. Li, W. Gu, L. Z. Zhang, J. Qu, Z. P. Ma, X. Liu, D. Z. Liao, Inorg. Chem. 2006, 45, 10425-10427; d) P. Thuéry, Polyhedron 2007, 26, 101-106; e) M. Frisch, C. L. Cahill, J. Solid State Chem. 2007, 180, 2597-2602; f) K. E. Knope, C. L. Cahill, Inorg. Chem. 2007, 46, 6607-6612; g) K. L. Ziegelgruber, K. E. Knope, M. Frisch, C. L. Cahill, J. Solid State Chem. 2008, 181, 373-381; h) P. Thuéry, CrystEngComm 2008, 10, 808-810; i) P. Thuéry, CrystEngComm 2010, 12, 1905-1911; j) C. E. Rowland, C. L. Cahill, Inorg. Chem. 2010, 49, 6716-6724; k) P. Thuéry, Inorg. Chem. 2011, 50, 1898-1904; 1) P. Thuéry, Eur. J. Inorg. Chem. 2013, 4563-4573; m) P. Thuéry, E. Rivière, Dalton Trans. 2013, 42, 10551-10558; n) P. Thuéry, J. Harrowfield, Inorg. Chem. 2015, 54, 8093-8102; o) N. P. Martin, C. Falaise, C. Volkringer, N. Henry, P. Farger, C. Falk, E. Delahaye, P. Rabu, T. Loiseau, Inorg. Chem. 2016, 55, 8697-8705.

[17] a) M. B. Andrews, C. L. Cahill, CrystEngComm 2011, 13, 7068-7078; b) K. E. Knope, H. Kimura, Y. Yasaka, M. Nakahara, M. B. Andrews, C. L. Cahill, Inorg. Chem. 2012, 51, $3883-3890$.

[18] See, for example: a) E. A. Mainicheva, A. A. Tripolskaya, O. A. Gerasko, D. Y. Naumov, V. P. Fedin, Russ. Chem. Bull., Int. Ed. 2006, 55, 1566-1573; b) J. X. Liu, Y. F. Hu, R. L. Lin, W. Q. Sun, X. F. Chu, S. F. Xue, Q. J. Zhu, Z. Tao, CrystEngComm 2012, 14, 6983-6989; c) X. Qin, X. L. Ni, J. X. Hu, K. Chen, Y. Q. Zhang, C. Redshaw, Q. J. Zhu, S. F. Xue, Z. Tao, CrystEngComm 2013, 15, 738-744; d) L. L. Liang, X. L. Ni, Y. Zhao, K. Chen, X. Xiao, Y. Q. Zhang, C. Redshaw, Q. J. Zhu, S. F. Xue, Z. Tao, Inorg. Chem. 2013, 52, 1909-1915; e) C. Y. Shan, W. X. Zhao, Z. Tao, Y. Q. Zhang, Inorg. Chem. 
Commun. 2016, 71, 109-112; f) L. M. Zheng, J. X. Liu, J. Solid State Chem. 2017, 245, 45-49.

[19] a) Y. Q. Zhang, Q. J. Zhu, S. F. Xue, Z. Tao, Molecules 2007, 12, 1325-1333; b) M. Sundararajan, S. K. Ghosh, J. Incl. Phenom. Macrocycl. Chem. 2012, 72, 437-441.

[20] R. W. W. Hooft, COLLECT, Nonius BV: Delft, The Netherlands, 1998.

[21] Z. Otwinowski, W. Minor, Methods Enzymol. 1997, 276, 307-326.

[22] G. M. Sheldrick, Acta Crystallogr., Sect. C 2015, 71, 3-8.

[23] G. M. Sheldrick, Acta Crystallogr., Sect. A 2015, 71, 3-8.

[24] L. J. Farrugia, J. Appl. Crystallogr. 1997, 30, p. 565.

[25] K. Momma, F. Izumi, J. Appl. Crystallogr. 2008, 41, 653-658. 
Table of Contents Entry

\title{
Uranyl Complexes as Scaffolding or Spacers for Cucurbit[6]uril Molecules in Homo- and Heterometallic Species, Including a Novel Uranyl-Lanthanide Complex
}

\author{
Pierre Thuéry
}

Key Topic: Uranyl complexes including cucurbit[6]uril

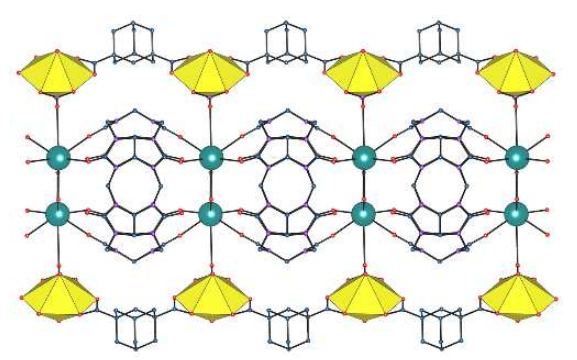

Three dicarboxylic acids and one disulfonic acid were used as ligands to generate four complexes containing uranyl cations and cucurbit[6]uril (CB6) molecules. In no case is uranyl directly bound to $\mathrm{CB} 6$, carbonyl groups being coordinated to $\mathrm{K}^{\mathrm{I}}$ or $\mathrm{Ce}^{\mathrm{III}}$ when present. One-dimensional polymers are formed in all cases, the uranyl-containing subunits assuming various roles, in particular as scaffolding for CB6-based columns or spacers in heterometallic complexes. 